\title{
Pesquisa em instituições de longa permanência para idosos: contribuições necessárias e possíveis
}

\author{
Research in long term care institution: necessary and possible contributions
}

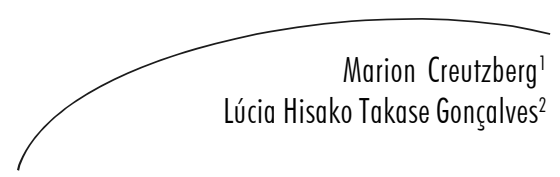

Resumo

O objetivo do estudo foi identificar os acoplamentos estruturais de Instituições de Longa Permanência para Idosos (ILPIs) com o sistema científico, por meio da percepção de dirigentes sobre a pesquisa nesse contexto, observando as comunicações e as ressonâncias na instituição. Estudo exploratório descritivo, qualitativo, com uso do método funcional de Niklas Luhmann. A coleta de dados utilizou observações de segunda ordem, por meio de entrevistas com sete dirigentes de instituições brasileiras sem fins lucrativos, de caráter público ou privado, que assinaram um Termo de Consentimento Livre e Esclarecido. A análise de conteúdo foi processada com base nos referenciais da teoria de sistemas de Niklas Luhmann. Existe o entendimento, dentre os dirigentes, da importância de investigações em ILPIs como contribuição à Gerontologia, mas há reservas em virtude da exposição indevida dos idosos, invasão de privacidade, retorno tênue das pesquisas para a instituição e o desconhecimento da pesquisa como ferramenta para transformação da prática. Ficam para a ciência e pesquisadores o desafio de iniciativas e proposições concretas de estratégias para a superação de limites na ILPI e o reconhecimento do profissional da instituição como capaz de contribuir para a construção de conhecimento.

\section{Abstract}

The study aims was to identify the structural couplings of Long Term Care Institution (LTCI) with the scientific system, through the perception of leaders about the research in this context, observing the communications and the resonances on the institution. It is a descriptive exploratory and qualitative research, using the Niklas Luhmann functional method. Data collection used second order observations by interviewing

\footnotetext{
Universidade Católica do Rio Grande do Sul (PUCRS). Faculdade de Enfermagem, Nutrição e Fisioterapia. Porto Alegre, RS, Brasil.

E-mail: marionc@pucrs.br

2 Universidade Federal de Santa Catarina. Departamento de Enfermagem. Florianópolis, SC, Brasil. E-mail: lucia.takase@pq.cnpq.br

Este artigo foi elaborado a partir de palestra proferida na VIII Jornada Brasileira de Enfermagem Geriátrica e Gerontológica realizada na Universidade do Estado do Rio de Janeiro, em abril de 2010.
}

Correspondência / Correspondence

Marion Creutzberg

E-mail: marionc@pucrs.br
Palavras-chave:

Instituição de Longa

Permanência para Idosos. Idoso. Envelhecimento. Teoria de sistemas. Pesquisa. 
seven managers of non-profit Brazilian institutions, either public or private. Content analysis was performed based on the references of Niklas Luhmann's systems theory. There is an understanding among the leaders of the importance of research in LTCI, as a contribution to gerontology, but there are doubts because of undue exposure of the elderly, invasion of privacy, fine return for the institution of research and lack of research as a tool for transformation practice. It is for science and research initiatives and the challenge of concrete propositions to strategies for overcoming limitations in the LPI and the recognition of professional institution as capable of contributing to the construction of knowledge.
Key words: Homes for the aged. Aged. Aging.

Systems theory. Research.

\section{INTRODUÇÃO}

A Instituição de Longa Permanência para Idosos (ILPI) é considerada um sistema social organizacional. Para Niklas Luhmann, autor no qual se fundamenta o presente estudo, sistemas sociais organizacionais ou organizações surgem da complexidade societal alcançada nas sociedades funcionalmente diferenciadas, para desenvolver atividades que se restringem ao cumprimento $\mathrm{e}$ satisfação de metas específicas e de muitas das necessidades humanas ${ }^{1}$ desempenhando uma função social. No caso da ILPI, a função de assistir ao idoso "quando verificada inexistência de grupo familiar, casa-lar, abandono ou carência de recursos financeiros próprios ou da família" 2 .

Um sistema social organizacional, a exemplo da ILPI, é um sistema autopoiético, que tem a capacidade de produzir e reproduzir a partir dele mesmo sua estrutura e os elementos que a compõem e está em contínuo acoplamento estrutural com seu entorno. $\mathrm{O}$ acoplamento estrutural compõe um dos conceitos centrais da Teoria de Sistemas de Luhmann ${ }^{3}$ e explica como se dá a relação entre a organização e o ambiente externo, ou seja, como as informações do ambiente são tomadas por informações no interior do sistema. Uma organização está acoplada a diferentes sistemas sociais, dentre os quais, o Sistema Científico.

O sistema parcial científico (Wissenschaff) é um sistema diferenciado pela função de produzir e obter conhecimento ${ }^{4}$. A ciência se projeta nos demais sistemas sociais por meio de diversos serviços que são assimilados por eles. A Tecnologia, por exemplo, torna-se um insumo da
Economia; as teorias de aprendizagem são assimiladas pelo sistema educacional; a Sociologia pela Política; a Biologia, na Saúde ${ }^{1}$. No Brasil, a capacidade de transferência do desenvolvimento científico-tecnológico para as políticas sociais e de saúde é avaliada como incipiente ${ }^{5}$, ao mesmo tempo em que se percebe a necessidade de priorizar o aumento de sua capacidade indutora ou de estimulação dos demais sistemas sociais. Esta capacidade diz respeito, também, às possibilidades de ampliar fomentos e recursos para a pesquisa.

O estudo teve por objetivo identificar os acoplamentos estruturais de ILPIs com o sistema científico, por meio da percepção de dirigentes sobre a pesquisa nesse contexto, observando as comunicações e as ressonâncias na instituição.

\section{METODOLOGIA}

Estudo de abordagem qualitativa, de cunho exploratório-descritivo. Adotou-se a Teoria de Sistemas de Luhmann como método analítico, denominado método funcional ${ }^{3}$.

O estudo teve como foco a ILPI do contexto brasileiro em meio urbano, com residentes sem condições de prover a própria subsistência ou provindas de famílias de baixa renda. Foram incluídas no estudo instituições regularmente reconhecidas como ILPIs, de caráter público ou privado e sem fins lucrativos.

A coleta de dados foi realizada por observações de segunda ordem, que é a auto-observação do sistema, na linguagem de Luhmann ${ }^{3}$. Essa observação foi realizada por meio de entrevistas, 
com a finalidade de compreender funções da ILPI, nem sempre percebidas por essas organizações. Foram entrevistados sete profissionais dirigentes de diferentes subsistemas internos de ILPIs, em três ILPIs, na região metropolitana de Porto Alegre, seguindo um roteiro de questões orientadoras, que abordavam se e como ocorre pesquisa nesse contexto e suas contribuições para a ILPI e para os idosos.

A análise dos dados teve, por referência, o método de análise funcional de Niklas Luhmann. Optou-se pelo método de Análise de Conteúdo ${ }^{6}$ para a análise do material textual, oriundo da transcrição das entrevistas. As unidades de significado identificadas no processo de análise de conteúdo foram codificadas, sendo que foi utilizada a letra $\mathrm{D}$ para identificar os dirigentes, seguidas de um número de identificação.

O estudo foi submetido ao Comitê de Ética em Pesquisa da PUCRS, que o aprovou através do Parecer $n^{\circ}$ 492/01-CEP. Os dirigentes das ILPI assinaram um Termo de Consentimento Livre e Esclarecido. Ainda nos dados obtidos nas comunicações de ILPIs, preservou-se a identidade da organização.

\section{APRESENTAÇÃO E ANÁLISE DOS DADOS}

A observação das ILPIs demonstrou que a relação do Sistema Científico com a instituição se dá, fundamentalmente, pela realização de pesquisas no âmbito da instituição. Ou seja, a IIPI, seus idosos e demais subsistemas são objetos de estudo, a exemplo da presente investigação.

Os dirigentes referiram-se ao desenvolvimento de investigações no contexto da ILPI. Expressaram a percepção da importância da pesquisa na evolução do conhecimento científico, neste caso, em Gerontologia:

'Eu acho que as pesquisas são fundamentais para a evolução. É claro, que amanhã seremos nós os velhos, as pesquisas são importantes. Eu acho assim, que a pesquisa tem que trazer algum benefício, não pra mim, mas sim pro idoso que isso venha acrescentar alguma coisa pra ele, alguma em beneficio a ele e que ele se sinta valorizado com essa pesquisa."(D1)

Estudos sobre a pesquisa do envelhecimento humano no Brasil ${ }^{7,8}$ apontaram um baixo dinamismo nessa área. Neste sentido, demonstraram que há ainda um percurso longo em direção à consolidação da pesquisa gerontológica no país, tornando pertinente a afirmação da dirigente quanto à importância da investigação no contexto do envelhecimento.

Uma busca, na Plataforma Lattes, por pesquisadores que estudam a temática das ILPIs demonstra um aumento nos últimos cinco anos. Utilizando as expressões asilo para idosos, Instituição de Longa Permanência para Idosos, obteve-se 138 e 35 pesquisadores, respectivamente, em 2005; já em 2010, essa mesma busca evidenciou 277 e 254 pesquisadores. Estes números poderiam ser considerados razoáveis frente ao fato de que a proporção de idosos residentes em ILPIs não ultrapassa $1,5 \%$.

Nas entrevistas, houve tanto expressões de que ainda são realizadas poucas investigações no contexto das instituições, como de que a busca pelo asilo como espaço de pesquisa tem aumentado nos últimos anos:

'Pouca, muito pouca, pesquisas, muito pouca pesquisa e seria um quadro fundamental pra desenvolver um bom trabalho, que a gente tivesse mais dados. "(D7)

"No ano passado a campanha da fraternidade era do idoso e ai todo mundo achou que era bom fazero trabalho sobre o idoso, então eu recebia por dia umas três ligações de enfermagem, psicologia, serviço social, administração, relações públicas, jornalismo e tudo que tu podia imaginar querendo fazer um trabalho sobre o asilo."(D4)

Quanto ao aumento das pesquisas no âmbito da ILPI, os dirigentes entendem que, se por um lado isso pode significar aumento de interesse pelo idoso, por outro pode resultar em exposição indevida e desnecessária do idoso institucionalizado. Do ponto de vista ético, as pesquisas devem levar em consideração a autonomia dos sujeitos, que devem consentir, por meio de Termo 
Consentimento Livre e Esclarecido, sua participação ${ }^{10}$. Nesse sentido, idosos moradores de instituições estão muito vulneráveis à invasão de privacidade, especialmente em se tratando de ILPI filantrópica, uma vez que, historicamente, são colocados em posição de desigualdade, vistos como incapazes de decidir, reagir ou emitir parecer acerca dos fatos.

Conforme expressou uma das dirigentes:

'Porque é a casa deles, então daqui a pouco, nós não vamos abrir as portas da casa deles porque é um bando de gente a ficarpasseando. A gente tinha uma das moradoras, ela era muito engraçada, um dia tava passando os alunos e ela disse: 'mas isso nem é zoológico, que vêm aqui e ficam olhando pra essas caras' e ai deram um presentinho pra ela e ela atirou pelajanela. E ela tinha razão!"'(D4)

"Tem que ter um cuidado, pra que os idosos não sejam usados demais, por isso tem que ter uma avaliação muito rigorosa."(D1)

De outra parte, houve críticas a determinados delineamentos e objetivos de pesquisas que, no entender dos dirigentes, só beneficiam o pesquisador e provocam ressonâncias negativas na ILPI, especialmente nos idosos, além da já comentada exposição indevida. Demonstram, com isso, a preocupação bioética que deve estar presente no planejamento de investigações com seres humanos. A regulamentação pela Resolução $n^{\circ}$ $169 / 96^{10}$ propõe assegurar a realização de investigações aceitáveis do ponto de vista moral, relevantes ao contexto social, cientificamente corretas e ecologicamente sustentáveis ${ }^{11}$. A posição receosa e preventiva da ILPI, no que se refere à realização de pesquisas em seu contexto, reflete a percepção social das práticas de pesquisa na qual se entende ser imprescindível a "prestação de contas" aos participantes, às instituições envolvidas e à sociedade como um todo.

As falas a seguir refletem, igualmente, o fato de que hoje a reflexão e a decisão acerca do ato de pesquisar ultrapassam as fronteiras das universidades e institutos de pesquisa ${ }^{11}$.
"O que a gente comenta muito, que verm muita pesquisa de questionário, tipo assim: 'tu gosta de morar aqui, tu te sente bem, com que idade foi a tua primeira relação sexual?' Sabe, então eles se sentem muito invadidos, eles se sentem desconfortável com isso. 'Tu gosta da comida, aqui a comida é boa?' Eu sei que nem na casa da gente eu gosto da comida às vezes que a gente faz, então são coisas assim eles se sentem desconfortados, e eles comentam muito isso com a gente."(D1)

"Porque as pessoas querem vir aqui e todas fazerem a mesma pergunta: tu ta abandonada aqui, eles são violentos aqui, como é que eles? Às vezues as pessoas me ligavam, entravam casa a dentro com questionário, saiam perguntando e a gente tinha que sair correndo dizendo que não pode. E as pessoas diziam 'como assim não pode?' 'A gente doa dez reais por mês, quando eu quiserperguntar eu vou lá perguntar', e várias coisas assim no sentido de retribuição. Não queriam devolver o material, terrivel! Eu acho que as pessoas não têm respeito, o idoso está numa instituição.”(D4)

O comentário dos dirigentes acerca de objetivos e instrumentos de coleta leva a identificar, pelo menos, três aspectos:

a) odesconhecimento de pessoas que se propõem a pesquisar, neste contexto, acerca do envelhecimento e as percepções equivocadas e negativamente marcadas acerca da ILPI;

b) a existência de conflitos de interesses entre o pesquisador e a instituição de idosos, a exemplo dos tradicionais conflitos entre protocolos e sujeitos pesquisados ${ }^{11}$. Diante disto, a Resolução n ${ }^{\circ}$ 196/96 expressa a obrigatoriedade de que seja assegurada a inexistência de conflito de interesses entre o pesquisador e os sujeitos da pesquisa ${ }^{10}$;

c) a percepção de pesquisadores, especialmente das ciências sociais, de que seus objetos, objetivos e métodos de pesquisa não necessitam se sujeitar às exigências éticas da Resolução $n^{\circ} 169 / 96$, como as pesquisas biomédicas, por exemplo. Em muitos pesquisadores, as exigências suscitam resistências e controvérsias. 
Schramm ${ }^{11}$, nesse sentido, discutiu a posição das ciências sociais quando se pensa que métodos frequentemente utilizados em pesquisas biomédicas sejam, necessariamente, mais invasivos. $\mathrm{O}$ autor exemplificou ponderando que, para um sujeito pesquisado pode ter peso igual, se não mais relevante, que seja protegida a privacidade das informações referidas a suas preferências, crenças e escolhas do que aquelas referentes a sua constituição e determinação biológica ${ }^{11}$.

Frente a situações como as descritas pelos dirigentes, as ILPIs têm restringido a realização de pesquisa, exigindo que as propostas lhes sejam apresentadas e autorizadas por elas. Para a operacionalização disto, algumas têm implantado comissões e normas para a avaliação de protocolos de pesquisa:

"Tem uma comissão permanente que foifundada, que é de avaliação. Funciona assim, tu tem que enviar uma proposta do teu projeto, com uma pequena autobiografia, porque isso vai pra análise. Se for possivel tu já anexa uma carta de próprio punbo onde tu vai dizer por que teu trabalho é bom pra instituição."(D4)

A autorização por parte da instituição é um procedimento correto e necessário frente às normas de pesquisa. A avaliação ou a concordância sobre a relevância da temática é, também, uma prerrogativa dos sujeitos e do local de realização dos estudos. Nesse sentido, expressaram:

"Pesquisas realizadas diretamente com idosos far seis meses que a gente não libera nenhuma. A gente avalia o que isso contribuipra instituição, porque saber quantos deles têm familia, quantos deles recebem visita, a gente tem controle disso, então ninguém precisa vir aqui pra pesquisar uma coisa que a gente já sabe."(D4)

"Até porque não é nosso interesse em pesquisar violência, esse tipo de coisa mais popular. É pesquisar coisas especificas, porque a gente sabe as coisas que acontecem aqui." (D6)

O objetivo primeiro dessas normas internas da ILPI é a proteção do idoso. A proteção é, com razão, fundamental, e evita que o idoso fique desamparado ou à mercê de terceiro ${ }^{11}$ em virtude de pesquisas. No entanto, os dirigentes referiram que esta posição tem sido mal interpretada, especialmente por acadêmicos de cursos de graduação das diferentes áreas de conhecimento:

"Só que às vezes os alunos não entendem, daí fica aquele estigma que a gente não quer mostrar a casa, que a gente enfrenta vários problemas, que a gente ta escondendo. Eles vêm aqui querem tirarfoto, querem filmar e não entendem que são medidas de proteção, 0 pessoal tem direito ao uso de imagem."(D4)

"Não a senhora não entendeu, eu só quero lhe fazer umas perguntas não precisa tudo isso" [submeter à avaliação]. (D4.51a)

A observação tem evidenciado que tais restrições têm realmente originado um certo malestar no meio acadêmico-científico, que se desagrada diante da recusa de realização de estudos considerados, por parte de quem os propõe, relevantes ao desenvolvimento do conhecimento em Gerontologia. Além disso, orientadores e orientados têm se deparado com pessoas, nas ILPIs, com compreensão aparentemente limitada a respeito dos processos de investigação e mesmo a respeito da pesquisa em Gerontologia.

Independentemente das ressonâncias internas da ILPI frente às solicitações para a realização de estudos com seus diferentes subsistemas internos, tais decisões devem ser respeitadas pela comunidade científica. Mesmo que as suspeitas de negação estejam relacionadas a possíveis irregularidades, como comentado pela dirigente, estas têm outros caminhos para serem desvendadas. Não há qualquer argumento a favor da imposição de uma pesquisa à instituição que não a aceita, assim como não há meios para exigir que os grupos que avaliam projetos, no âmbito das ILPIs, tenham a mesma qualificação e composição de Comitês de Ética e Pesquisa, por exemplo.

Ainda assim, se a pesquisa autorizada pela ILPI revelar limites e dificuldades da instituição, há que se respeitar os procedimentos éticos. $\mathrm{O}$ 
compromisso com o retorno dos dados à instituição poderá contribuir com a proposição de estratégias para sua superação, que serão, ou não, selecionadas pela organização.

Uma reflexão provinda dos dirigentes revela um aspecto, aparentemente pouco considerado na comunidade científica, e talvez um dos motivos pelos quais pesquisadores, provindos dos meios acadêmicos, muitas vezes numa postura de detentores da verdade ${ }^{12}$, sejam vistos como conspirações contra os leigos ${ }^{11}$ :

"E até está se tentando reestruturar algumas coisas. Nós não queremos daqui bá um tempo, nós não vamos poder mais somente ficar recebendo pesquisadores. Nós também temos condições de dar e eles [os idosos] e a casa num todo, contribuir pra comunidade. Nós temos aqui, mantemos já um conbecimento do atendimento ao idoso, que acho que dá pra se considerar que é primazia em atendimento. E eu acho que a gente tem que abrir a casa quando vamos sair, isso a gente tem que ensinar pras pessoas, isso é uma contribuição pra comunidade."(D4)

A presença da academia se dá frequentemente por meio do desenvolvimento de projetos de pesquisa ao lado de sua inserção em atividades de ensino e extensão. No discurso da academia, perpassa a preocupação com a transformação da realidade, mas as iniciativas e a projeção concreta do saber acadêmico nos serviços ainda parecem tênues ${ }^{12}$.

A pesquisa, no entanto, pode ser estratégia importante para a melhoria da prática assistencial, pois esta, espera-se, tem origem nos problemas vivenciados por professores, alunos e profissionais no cotidiano da instituição. Nesse sentido, a fala abaixo colocou a ILPI não só como fonte de conhecimento a ser construído por outros, mas ela mesma como produtora de conhecimento, indicando aimportância de que os profissionais sejam envolvidos nos processos de pesquisa, como pesquisadores, coautores do conhecimento produzido:

"Na verdade assim, nós temos o nosso grupo interno de profissionais que são profissionais que exploram os seus atendimentos, então temos o nosso médico que leva pros seminários casos daqui. Nós fomos pra jornada da SBGG, também com uma ideia de divulgar. Então assim, prioritariamente se eu tenho profissionais internos, apesquisa do conbecimento que eu tenho aqui vai ter que serfeita pela gente entendeu e a gente tem como demandar isso."(D6)

Ao que parece, poucas vezes o profissional, na ILPI, é visto como alguém interessado e capaz de produzir. Por outro lado, o profissional em campo pode não compreender a pesquisa como ferramenta para transformação da prática. Esta percepção será certamente ampliada no aprofundamento dos acoplamentos estruturais entre a ILPI, o sistema educacional e o sistema científico. As comunicações, em todas as direções, precisam ser mais bem observadas pelos respectivos sistemas. Uma das comunicações imprescindíveis é o retorno da pesquisa, por parte do sistema científico, para a ILPI. Esta é uma queixa, um desconforto expresso pelos seus dirigentes: “Não, não, não retornam, não [as pesquisas]”. (D1.28)

A observação tem indicado que tais retornos, em algumas situações, até são disponibilizados à ILPI, mas, ao que parece, permanecem como informações não compreendidas, e por isso, não selecionadas pela instituição.

\section{CONSIDERAÇÕES FINAIS}

A ressonância do aumento de pesquisas, na relação da ILPI com o sistema científico, gerou tanto a concordância quanto o questionamento entre os dirigentes. A concordância esteve no entendimento da importância de investigações que contribuam para a Gerontologia. Os questionamentos se relacionaram à exposição indevida dos idosos, invasão de privacidade, retorno tênue das pesquisas para a instituição e o desconhecimento da pesquisa como ferramenta para transformação da prática. No sistema científico, a ressonância frente à negativa gera incompreensão e mal-estar.

Ficam para a ciência e pesquisadores o desafio de iniciativas e proposições concretas de estratégias 
para a superação de limites na ILPI e o reconhecimento do profissional da instituição como capaz de contribuir para a construção de conhecimento. O uso de metodologias participativas na investigação pode facilitar a implantação de mudança a partir da pesquisa.

\section{REFERÊNCIAS}

1. Rodríguez D, Arnold M. Sociedad y teoría de sistemas. Santiago de Chile (CL): Editorial Universitaria; 1990.

2. BRASIL. Senado Federal. Lei $N^{\circ} 10.741$, de 10 de outubro de 2003. Estatuto do Idoso. Brasília, (DF); 2003.

3. Luhmann N. Soziale system3.Luhmann N. Soziale systeme: Grundri âeiner allgemeinen theorie. Frankfurt; (DE): Suhrkamp; 1984.

4. Corsi G, Espósito E, Baraldi C. Glóssario sobre la teoría social de Niklas Luhmann. México: Universidade Iberoamericana; ITESO; Barcelona: Editorial Anthropos; 1996. 192 p.

5. Guimarães R. Bases para uma política nacional de ciência, tecnologia e inovação em saúde. Ciên Saúde Coletiva. 2004 abr-jun; 9(2):375-87.

6. Moraes R. Análise de conteúdo: limites e possibilidades. In: Engers ME (org.). Paradigmas e metodologias de pesquisa em educação. Porto Alegre: EDIPUCRS; 1994.

7. Prado SD, Sayd JD. A pesquisa sobre envelhecimento humano no Brasil: pesquisadores, temas e tendências. Ciên Saúde Coletiva. 2004 jul-set [acesso em 2005 Jan 10]; 9(3):763-72. Disponível em http:// www.scielo.br/ scielo.php?script $=$ sci_arttext\&pid $=\mathrm{S} 1413$ $81232004000300027 \& \bar{l} \operatorname{lng}=$ pt\&nrm $=$ iso.
8. Prado SD, Sayd JD. A pesquisa sobre envelhecimento humano no Brasil: grupos e linhas de pesquisa. Ciên saúde coletiva. 2004 jan-mar [acesso em: 2005 Jan 10]; 9(1):57-67. Disponível em: http://www.scielo.br/ scielo.php?script $=$ sci_arttext\&pid $=$ S1413$81232004000100006 \& \overline{\mathrm{l}} \mathrm{ng}=\mathrm{pt \& nrm}=$ isso.

9. Creutzberg M. A Instituição de Longa Permanência para Idosos e sua relação com o sistema societal: uma análise na perspectiva da Teoria de Sistemas de Niklas Luhmann. [tese]. Porto Alegre (RS): Instituto de Geriatria e Gerontologia; PUCRS; 2005.

10. Ministério da Saúde (BR). Resolução n.196, de 16 de outubro de 96 . Diretrizes e normas regulamentadoras de pesquisas em seres humanos. Brasília(DF); 1996.

11. Schramm FR. A moralidade da prática de pesquisa nas ciências sociais: aspectos epistemológicos e bioéticos. Ciênc saúde coletiva. $2004 \mathrm{jul} / \mathrm{set}$ [acesso em 2005 Jan 10]; 9(3):773-84. Disponível em: http:// www.scielo.br/ scielo.php?script $=$ sci_arttext\&pid $=$ S1413$81232004000300028 \& \overline{l n} \mathrm{n}=\mathrm{pt} \& \mathrm{nrm}=$ isso.

12. Ojeda BS, Santos BRL, Eidt OR. A integração ensino e assistência na enfermagem: delineando possibilidades para uma prática contextualizada. Acta Paulista Enf. 2004 out- dez; 17(4):432-8. 
